\title{
A Practical Introduction to Network Neuroscience for Communication Researchers
}

\author{
Jacob T. Fisher, ${ }^{1}$ Frederic R. Hopp, ${ }^{2}$ René Weber ${ }^{2 *}$
}

\begin{abstract}
The increasing adoption of brain imaging methods has greatly augmented our understanding of the neural underpinnings of communication processes. Enabled by recent advancements in mathematics and computational infrastructure, researchers have begun to move beyond traditional univariate analytic techniques in favor of methods that consider the brain in terms of evolving networks of interactions between brain regions. This network neuroscience approach is a potential boon to communication and media psychology research but also requires a careful look at the complications inherent in adopting a novel (and complex) methodological tool. In this manuscript, we provide an overview of network neuroscience in view of the needs of communication neuroscientists, discussing considerations that must be considered when constructing networks from neuroimaging data and conducting statistical tests on these networks. Throughout the manuscript, we highlight research domains in which network neuroscience is likely to be particularly useful for increasing theoretical clarity in communication and media psychology research.
\end{abstract}

\section{Introduction}

Communication scholars draw on a wide range of multidisciplinary methods to understand how humans create, transmit, and understand messages. The introduction of neuroimaging into communication research has produced notable advancements in how we research persuasion (Falk, Berkman, et al., 2010), flow (Harris et al., 2017; Huskey, Craighead, et al., 2018; Weber et al., 2009), attention/cognitive control (Huskey, Craighead, et al., 2018; Weber, Alicea, et al., 2018), political information processing (Falk et al., 2012; Schmälzle et al., 2015), information sharing (Baek et al., 2017; C. Scholz et al., 2017), media violence (Mathiak \& Weber, 2006; Weber et al., 2006), social media (Meshi et al., 2015, 2016), social interaction (Schilbach et al., 2006; Stephens et al., 2010), and interpersonal synchrony (Cacioppo et al., 2014; Hasson et al., 2012).

These pioneering brain imaging studies in communication had two primary goals: First, researchers were interested in isolating the neural correlates of communication-relevant processes. Second, these studies sought to understand how activation in the brain during message processing precedes, mediates, or is the result of communication processes-most notably behavior and attitude change (Falk, Berkman, et al., 2010; Falk, Rameson, et al., 2010; Huskey et al., 2017). This work revealed-among many other things-the central importance of reward processing regions like the medial prefrontal cortex ( $\mathrm{mPFC}$ ) and orbitofrontal cortex (OFC; Falk, Rameson, et al., 2010; Schultz et al., 1997) for message reception and valuation, the recruitment of regions associated with mentalizing and social information processing (like the temporoparietal junction (TPJ) and precuneus (Frith \& Frith, 2006; Schilbach et al., 2008; J. Scholz et al., 2009) in perspective-taking and message sharing, the role of the anterior cingulate cortex (ACC; Huskey, Craighead, et al., 2018) for attention and flow during media use, and the involvement of the ACC and the amygdala during violent video game play (Mathiak \& Weber, 2006; Weber et al., 2006).

\footnotetext{
${ }^{1}$ College of Media, University of Illinois Urbana-Champaign

${ }^{2}$ Media Neuroscience Lab, Department of Communication, University of California Santa Barbara

* Please address correspondence to: renew [at] ucsb [dot] edu
} 
This focus on univariate brain activation maps has catalyzed much progress in communication research. As such, these methods have been reviewed extensively within the literature (Falk, 2012; Hopp \& Weber, 2020; Schmälzle \& Meshi, 2020; Turner et al., 2018; Weber, 2015; Weber, Fisher, et al., 2018). However, the relationship between brain activity and behavior is much more complex than can be described in terms of contiguous regions of activation on a cortical map (Huskey, 2016). Even relatively simple cognitive processes recruit many brain regions across broad swaths of cortical and subcortical space. Furthermore, the activation of any one region of the brain often cannot be understood without considering how other regions activate (or deactivate) in concert with it (Bassett \& Gazzaniga, 2011). This is especially the case for communication processes, which are complex amalgamations of relatively simpler cognitive and emotional processes (Mathiak \& Weber, 2006; Weber et al., 2008).

In the last decade, neuroscience researchers have developed a collection of methods that push beyond univariate approaches to investigate how coordinated activity across multiple brain regions relates to human cognition and behavior. These methods have come to be collectively known as network neuroscience (Bassett \& Sporns, 2017). Network neuroscience methods are a potential boon to communication and media psychology research but also require a careful look at the complications inherent in adopting a novel (and complex) methodological tool (Turner et al., 2018). In this manuscript, we provide an overview of network neuroscience in view of the needs of communication neuroscientists and the broader research community investigating brain activity during naturalistic tasks. We highlight the promise and potential pitfalls of these methods, discussing considerations that must be considered when constructing networks from neuroimaging data and conducting statistical tests on these networks. Throughout the manuscript, we highlight research domains in which network neuroscience is likely to be useful for increasing theoretical clarity and integrating across topic domains.

\section{Introduction to Network Neuroscience}

The brain has been described as a dynamic network of interconnected units since at least the 19th century (Cajal, 1911; Swanson \& Lichtman, 2016), but only recently have advancements in mathematics and computing infrastructure allowed researchers to examine networks of activity in living human brains. In general, these networks are constructed using patterns of statistical covariance between different regions of the brain and analyzed using techniques developed from a branch of mathematics known as graph theory (Rubinov \& Sporns, 2010). This research has facilitated increased empirical understanding of many complex cognitive processes (Bassett, Xia, et al., 2018; Bassett \& Sporns, 2017; Medaglia et al., 2015) and of the systems-level neural mechanisms underlying human behavior (Bertolero \& Bassett, 2019). The brain networks that are investigated using these methods can be grouped into two primary categories: intrinsic networks and task-evoked networks.

\subsection{Intrinsic Networks}

Large populations of neurons throughout the brain fire synchronously with one another, even in the absence of an external task or sensory input (Raichle et al., 2001; 2015). These synchronous response patterns comprise an intrinsic network with a structure that strongly reflects anatomical connections in the brain (Biswal et al., 2010; Honey et al., 2009). Intrinsic networks have a relatively stable architecture across individuals (Yeo et al., 2011) but also exhibit meaningful inter-individual variability (Gratton et al., 2018). This "functional fingerprint" (Finn et al., 2015) is unique to an individual and seems to be both heritable and stable across the lifespan (Elliott et al., 2019; Horien et al., 2019).

Individual differences in intrinsic connectivity predict variables that are often of interest to communication scholars, including age (Betzel et al., 2014; Cao et al., 2014), social network size (Bickart et al., 2012), willingness to share self-related information (Meshi et al., 2016), decisions to reciprocate in social interactions (Cáceda et al., 2015), executive functioning ability (Reineberg et al., 2015), and mental 
disorders like ADHD (Elton et al., 2014; Konrad \& Eickhoff, 2010; Yu-Feng et al., 2007), schizophrenia (Rashid et al., 2016; Su et al., 2016), and dementia (Rombouts et al., 2009). In addition, emerging work suggests that intrinsic network connectivity can be used to predict an individual's responsiveness to health-related interventions (Gabrieli et al., 2015). As such, communication and media psychology theory stands to benefit from research paradigms that investigate how individual differences in intrinsic connectivity patterns relate to message processes and outcomes.

\subsection{Task-evoked Networks}

Task-evoked networks are constructed from patterns of statistical covariance that occur between different brain regions whenever the brain is engaged in a specific task, such as movie viewing, interpersonal communication, or learning. Network structure during a task predicts performance in a wide array of cognitive measures and highlights individual differences in brain activity that are not observable from intrinsic connectivity data alone (Finn et al., 2017; Vanderwal et al., 2017). Additionally, task-evoked networks have been shown to be more reliable than those observed at rest (Wang et al., 2017). As such, research paradigms relating task-evoked network structure to communication variables of interest are likely to be widely applicable for addressing questions relevant to communication researchers.

Of special interest is the substantial body of literature investigating network connectivity during movie viewing and other naturalistic tasks (Bottenhorn et al., 2019; Hasson et al., 2008, 2012). Indeed, a rapidly growing body of work within communication and cognate fields has begun to investigate how task-evoked functional connectivity can provide additional insight into communication processes and effects. Taskevoked connectivity while processing anti-smoking and anti-drug public service announcements has been shown to predict health-related behavior change (Cooper et al., 2017, 2018) and to be modulated by drug use risk (Huskey et al., 2017). Task-evoked networks have also been used to investigate flow experiences during video game play (Huskey, Wilcox, et al., 2018), interpersonal understanding and friendship (Parkinson et al., 2018; Wheatley et al., 2019), effective narrative processing in movies (Aly et al., 2018; Andric et al., 2016) and attention and comprehension within spoken/written stories (Regev et al., 2018; Simony et al., 2016).

\section{Communication Questions to Address with Network Neuroscience}

\subsection{Understanding Individual Differences}

Network neuroscience methods can enable researchers to investigate how individual differences in communication processes and outcomes relate to individual differences in synchronized activity across multiple brain regions. A group of individuals watching the same message will, in general, produce quite similar patterns of brain activation (Hasson et al., 2008). Intersubject variation in these patterns corresponds with variation in the way the message is processed, including how it is comprehended and stored in memory (Simony et al., 2016) and whether it is persuasive to that individual (Cooper et al., 2018). For example, greater connection strength within the default mode network (DMN) during narrative processing is associated with increased memory for the narrative in follow-up tests. Furthermore, activity within this network varies in a manner dependent on the interpretive framework that is applied to the narrative (Yeshurun et al. 2017).

In a similar way, individual differences in task-evoked brain networks may help us understand a number of other individual differences germane to communication and media psychology research. Connectivity metrics allow for a much richer characterization of an individual's "functional fingerprint" (Finn et al., 2015) than do univariate approaches, suggesting their utility for investigating long-standing questions. Indeed, network methods are already contributing to our understanding of individual differences in emotion (Kong et al., 2019; Pessoa et al., 2017), motivation (Di Domenico \& Ryan, 2017), attention 
(Rosenberg et al., 2017), persuasion (Cooper et al., 2017; Huskey et al., 2017), and aggression (Klasen et al., 2013; Weber et al., 2006), among many others.

\subsection{Highlighting Biological Mechanisms}

Second, network neuroscience measures are likely to be useful for proposing candidate mechanisms to add explanatory power to communication concepts in light of dynamic neural processes. Communication scholars often call for a deeper study of the mechanisms that underlie communication phenomena (Valkenburg \& Peter, 2013). At the same time, communication is a dynamic process concurrently involving multiple cognitive systems, making simple mechanistic explanations unlikely or even impossible. As has been demonstrated in related fields (Bertolero \& Bassett, 2019), network methods uniquely exploit the properties that make a system complex, using these emergent properties to foster richer explanations and to compress information in a way that still maintains essential characteristics of the system (Rathkopf, 2018), while avoiding the trap of overly simplistic, low-dimensional representations (Jolly \& Chang, 2019).

Incorporating networked processes in the brain as candidate mechanisms undergirding various facets of message processing can help us understand how temporal variation in brain networks relates to differences in message processing outcomes like memory, persuasion, and learning. Several examples of the utility of this approach can already be found within the communication literature. First, Huskey, Wilcox, and Weber (2018) highlight efficiency-the inverse of the average shortest path length between nodes-in task-evoked brain networks as a key factor in understanding how intrinsic reward relates to attention and cognitive control during video game play. Relatedly, work by Cooper and colleagues (2018) has demonstrated that the flexibility of nodes in default mode and frontoparietal networks while viewing anti-smoking images is associated with smoking reduction, suggesting that integration between these two networks may support persuasion and intention-change processes. Finally, a recent investigation by Weber and colleagues (2018) indicates that connectivity in attention-related brain networks is attenuated in a non-linear fashion in response to increasing distraction, hinting at a candidate mechanism undergirding the commonly-observed curvilinear relationship between attention and increasing cognitive demands.

\subsection{Bridging Sub-Domains}

Finally, network neuroscience approaches can provide a common analytic framework for bridging interesting questions at multiple scales, serving to integrate seemingly disparate research domains (Bassett \& Sporns, 2017). Network neuroscience measures have allowed researchers in the neurosciences to develop a more thorough understanding of the rich landscape of factors involved in their phenomena of interest (Bertolero \& Bassett, 2019), enabling convergence across fields that had historically operated in relative isolation from one another (Bassett, Zurn, et al., 2018; Betzel \& Bassett, 2017). Network neuroscience measures hold similar promise for creating bridges across communication subfields (Craig, 1993), and between communication science and the psychological and brain sciences (Weber et al., 2015).

Indeed, network neuroscience tools are already enabling research at the intersection of message processing and social network analysis-two formerly disparate areas of communication and social psychological research. This work has revealed (among other things) that response inhibition in adolescents is moderated by both brain connectivity and social network structure (Tompson et al., 2018) and that social network positioning influences the neural underpinnings of message sharing decisions (O’Donnell et al., 2017; C. Scholz et al., 2017), feelings of social exclusion (Bayer et al., 2018; Schmälzle et al., 2017), and relational closeness (Parkinson et al., 2018). Although this research is still in its incipient stages, it has already produced notable advancements in our understanding of how social networks interact with brain networks to influence communication processes and predict responses to messages. 


\section{Building a Network}

As is clear from the preceding research, network neuroscience methods are increasingly being applied to problems of interest to scholars in communication and cognate fields. In this section, we provide an overview of the steps that are necessary for constructing a network from functional neuroimaging data and conducting basic statistical tests on brain networks. Space does not permit an exhaustive overview of the software tools that have been (and are being) developed to implement these techniques. As such, communication researchers interested in learning more about specific tools that may be useful in each of these steps may consult Abraham et al. (2014), Ciric et al. (2018), Nastase et al. (2019); Rubinov and Sporns (2011), and Sizemore and Bassett (2011).

\subsection{Preprocessing}

Like any fMRI method, network neuroscience research requires an extensive preprocessing pipeline before data may be subjected to statistical analysis. In addition to the standard preprocessing steps (as conducted using fMRIprep (Esteban et al., 2019) or another well-documented processing pipeline), network neuroscience analyses require extra consideration in two primary areas of preprocessing. The first of these involves dealing with the high levels of autocorrelation present in brain imaging data (Honari et al., 2019; Jo et al., 2010; Lund et al., 2006; Zarahn et al., 1997). Autocorrelation can artificially inflate connectivity estimates, contributing to statistical confounds that can cloud the relationship between observed connectivity patterns and variables of interest within an experimental design (Afyouni et al., 2019). For this reason, pre-whitening (removing temporal autocorrelation) has been recommended before conducting network analysis of task-based brain imaging data (Bright et al., 2017; Honari et al., 2019; Liégeois et al., 2017).

Another pertinent preprocessing step is the removal of motion artifacts (Power et al., 2012). Even very small movements like breathing, cardiac activity, and eye movements during fMRI scanning can create confounds in connectivity-based analyses (Van Dijk et al., 2012). In what is likely to be good news for communication and media researchers, a growing body of evidence suggests that fMRI paradigms involving movies and other naturalistic stimuli produce relatively fewer motion confounds compared to resting state or trial-based paradigms (Vanderwal et al., 2017; 2019). Even so, removal of motion confounds is critical in any preprocessing pipeline. A large body of work in recent years has sought to ascertain best practices for the removal of motion confounds (Ciric et al., 2017; Lydon-Staley et al., 2019). This has resulted in the recent release of the $x c p E n g i n e^{3}$ software package to conduct further denoising on data that have been preprocessed with fMRIprep. For most communication and media psychology scholars, these standardized pipelines are sufficient for preprocessing needs and carry with them the added benefit of increasing reproducibility and opportunities for data sharing.

\subsection{Defining Nodes}

Once brain imaging data have been preprocessed, a researcher must decide how to define the nodes in the network. For fMRI data, nodes are typically defined as either voxels ${ }^{4}$ or regions of interest (ROIs) spanning multiple voxels. Defining a node as a voxel (or an individual sensor in an EEG or MEG paradigm) has the advantage that it does not require further aggregation than is already inherent in the data by nature of its resolution. This reduces the number of assumptions as to how well the nodes in the network correspond to neuronal populations of interest. Unfortunately, creating nodes in a voxel-wise fashion also comes with a few disadvantages. First, the size of a voxel has nothing to do with the underlying neurons and everything to do with the resolution of the scanner that collected the data. As such, a relevant cluster

\footnotetext{
${ }^{3}$ https://xcpengine.readthedocs.io/

${ }^{4} \mathrm{~A}$ voxel is a "volume pixel", a 3-dimensional chunk of the brain usually measuring between $1 \mathrm{~mm}^{3}$ and $3 \mathrm{~mm}^{3}$.
} 
of neurons may be split into multiple voxels, and one voxel may contain multiple clusters of neurons with varying functions and connectivity patterns (Eickhoff et al., 2018; Wig et al., 2011). Because fMRI measures index neuronal activation in terms of the flow of oxygenated blood, signals are often spread out across multiple voxels, creating artificial inflation of connectivity measures between neighboring voxel nodes (Power et al., 2011). Furthermore, spatial smoothing measures commonly employed in fMRI preprocessing pipelines have a non-trivial effect on network topology in networks in which nodes are defined in a voxel-wise fashion (Alakörkkö et al., 2017; Uğurbil, 2016). Finally, voxel-based networks often require enormous computing power (Loewe et al., 2016). Although researchers increasingly have access to cloud-based analysis platforms that can reduce barriers to entry, ${ }^{5}$ voxel-based connectivity analyses may still be computationally intractable for many researchers. For these reasons, many approaches designed to investigate task-evoked networks define nodes at the ROI level (for a conceptual schematic of the steps involved in creating a dynamic network from brain data, see Figure 1).

ROIs are most often defined using structural or functional parcellation atlases of brain regions. These atlases are typically constructed and validated using high-resolution neuroimaging datasets. Structural parcellation atlases, which are based on anatomic divisions marked by hills (gyri) and valleys (sulci) in the brain, tend to perform quite poorly for constructing functional networks (Craddock et al., 2012). For this reason, functional atlases are often used to define nodes in task-evoked networks (Cole et al., 2014). These atlases divide the brain into a number of 3-dimensional brain areas based on differentiable patterns of brain activity at rest or during particular tasks. Of these, four of the most common are a 264-node atlas developed by Power and colleagues (Power et al., 2011), a 300-node atlas developed by Shen and colleagues (Shen et al., 2013), a 360-node atlas developed by Glasser and colleagues (Glasser et al., 2016) and a "multiresolution" atlas proposed by Craddock and colleagues (Craddock et al., 2012).

Defining nodes at the ROI level greatly reduces the dimensionality of the resulting network-from thousands of nodes down to hundreds or fewer-but can affect the topology of the network and the replicability of findings (Eickhoff et al., 2018; Hayasaka \& Laurienti, 2010). As the number of nodes in a network increases, the replicability of functional connectivity measures also tends to increase, but this often comes at the cost of interpretability (Craddock et al., 2012) and is severely limited by the computational infrastructure available to most researchers (Loewe et al., 2016). For this reason, it is important to consider the number of nodes that will likely be most beneficial for the chosen topic and analysis method. Although fine-grained analyses may seem more statistically reliable, the current resolution of functional brain imaging only permits interpretation of connectivity at a relatively coarse level (Wig et al., 2011). A "happy medium" on this continuum seems to be between 200 and 500 nodes (Shen et al., 2010), but best practices in this area are still actively developing, and there does not exist a parcellation scheme that adequately addresses all challenges (Arslan et al., 2018). For this reason, we recommend that communication scholars interested in conducting network analyses rely on wellvalidated and widely-used atlases such as those provided by Power et al., (2011), Shen et al., (2010), Craddock et al., (2012), or Glasser et al., (2016).

\footnotetext{
${ }^{5}$ Promising entries in this domain include brainlife.io (https://brainlife.io), Flywheel (https://flywheel.io), and Google Colaboratory (https://colab.research.google.com).
} 

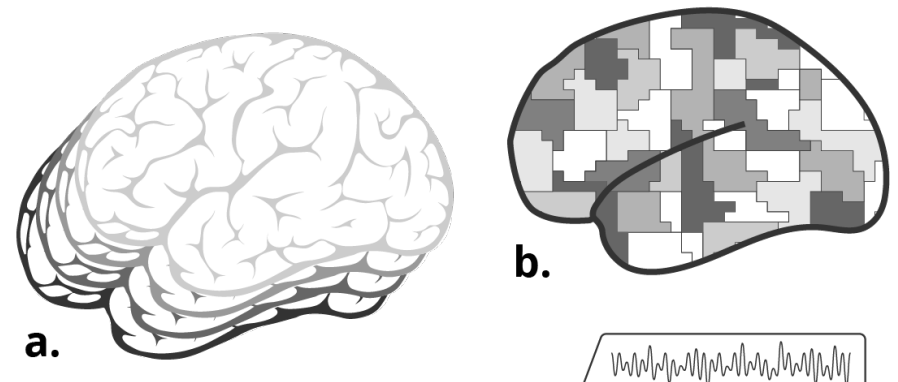

a.

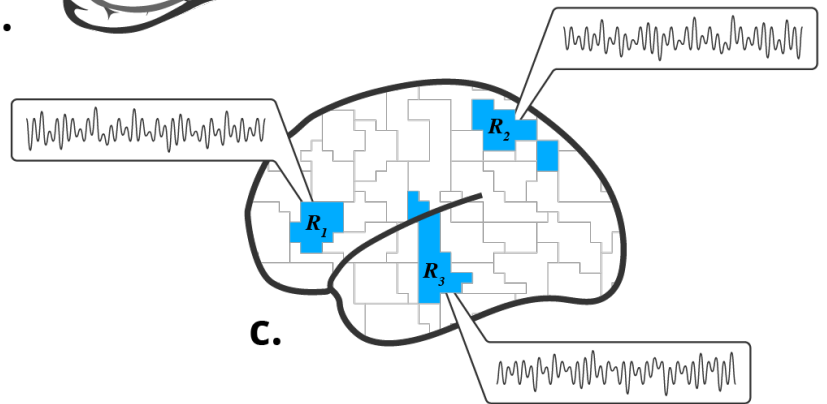

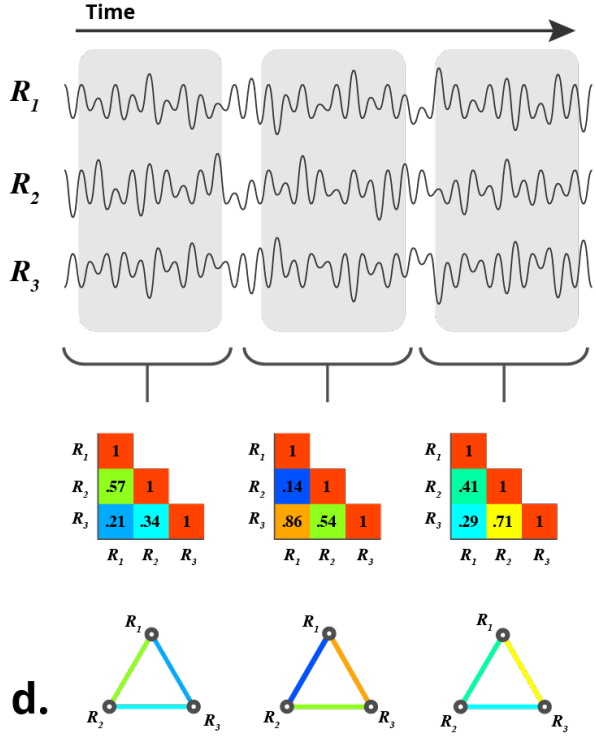

Figure 1: Conceptual schematic of the steps involved in creating a dynamic network from brain data. a) Acquiring imaging data using brain imaging techniques (EEG, fMRI, fNIRS, etc.). Functional data can be collected during a particular task (such as watching a movie or playing a video game), or when the participant is at rest.; b) parcellating brain imaging data into ROIs using a validated parcellation atlas (e.g. Craddock et al., 2012; Glasser et al., 2016; Power et al., 2011; Shen et al., 2010). If using a voxel-based approach, parcellation is not necessary; c) Extract time series from each ROI or voxel of interest. For a whole-brain analysis, the time series is extracted from all ROIs; $d$ ) if constructing a dynamic network, divide scanning run into chunks, or create a sliding window across all times; e) extract the statistical relationship (e.g., correlation) between each node and every other node in the network. These statistical dependencies can be analyzed in the form of a matrix, also called the network adjacency matrix, and visualized as a network.

\subsection{Defining Edges}

Once the nodes of the network are defined, a researcher must decide how to define the connections between them. The most intuitive and interpretable approach is to consider anatomical connectionsknown links between neurons as traced using invasive neurophysiological measures or using white matter pathways imaged through diffusion tensor imaging (DTI) or diffusion spectrum imaging (DSI; Fornito et al., 2016). Unfortunately, neither of these measures can non-invasively capture dynamic activation of functional networks in living human brains. As such, the most common approach is to consider edges as defined by statistical relationships between the activation time series of each node (Sporns, 2010; Wig et al., 2011).

One widely used method to construct edges is a simple Pearson correlation (Power et al., 2011; Shen et al., 2010; Zalesky et al., 2012). A time series of brain activity at one node is extracted and correlated with the time series of another node, resulting in an edge between the two nodes that is weighted by the correlation coefficient. This process is repeated for every possible pair of nodes in the network. The resulting correlations are typically entered into a matrix wherein rows and columns correspond to individual nodes, and cells of the matrix contain the correlation between the two nodes (Rubinov \& Sporns, 2010; Zalesky et al., 2012). Lending credence to the biological validity of these networks, these correlation-based networks 
have been shown to be highly reliable within individuals (Choe et al., 2017), even across different scan parameters (Abrol et al., 2017).

Constructing edges between nodes based on single correlation coefficients has been shown to systematically bias certain network parameters (Afyouni et al., 2019; Zalesky et al., 2012). For this reason, some employ alternative measures for connectivity, including wavelet coherence, multivariate connectivity, and mutual information approaches (Anzellotti \& Coutanche, 2018; Bressler \& Menon, 2010; Bullmore \& Sporns, 2009; Chang \& Glover, 2010; Hutchison et al., 2013). These methods can correct some of the issues inherent in using Pearson correlation, but they come with their own complications and can add considerable complexity to analyses (Fornito et al., 2013; Jalili, 2016; Wig et al., 2011). It is worth emphasizing that all of these measures create undirected edges between two nodes. Those interested in examining causal influence processes in brain networks must use other methods, such as multivariate time series analysis combined with concepts that define fundamental principles of causal inferences (such as Granger causality; Eichler, 2013; Roebroeck et al., 2005), or other networked causality methods, although the usefulness of these methods in brain networks is still under active investigation (Bielczyk et al., 2018).

\subsection{Time-Varying Networks}

When creating a network from brain imaging data, one can calculate the statistical relationships between nodes averaged across the duration of a period of interest (e.g., a trial, a run, or an entire scan), generating a static snapshot of the statistical relationships between nodes observed during the period. Often, though, a researcher is interested in how networks evolve throughout the course of a task. The simplest way to construct a time-varying network is to break up the period of interest into intervals and calculate relationships between each node for each time interval (Zalesky et al., 2014). This can readily be done whenever an experiment lends itself to temporal chunking (such as when it consists of a number of trials presented in succession). This approach is often used to construct multilayer networks in which nodes in each time window are connected to the same node in adjacent time windows (Mucha et al., 2010). Many experiments, though, do not lend themselves to such a time-blocked approach. This is especially true for naturalistic stimuli of interest to communication scholars. Movies, video games, and interpersonal communication tasks usually evolve smoothly over time rather than in discrete chunks. For these sorts of paradigms, an approach is needed that can calculate how a network also smoothly evolves over time.

One widely used method for creating a temporally evolving network is the sliding window method (Zalesky et al., 2014). In this approach, connectivity is calculated for all nodes within a time window. After this, the window is moved forward one time step, and connectivity is calculated again. This is repeated for all time points in the run. The width of the window and the offset parameter that are chosen can influence network measures of interest. Window widths that are too narrow carry with them the risk of observing spurious fluctuations in connectivity (Hutchison et al., 2013; Leonardi \& Van De Ville, 2015; Zalesky \& Breakspear, 2015), whereas window lengths that are too long risk missing key variation in network topology that may be relevant for understanding the phenomenon investigated in the study (Preti et al., 2017). Although there is no universally accepted best practice for these values at this time, a window width between 30 and 60 seconds (combined with a high-pass filter of 1 divided by the window length) has been suggested for optimal stability of functional connectivity estimates (Leonardi \& Van De Ville, 2015). As with other network construction steps, the width of the time window should be set carefully in light of particular questions of interest (Shakil et al., 2016). For communication scholars, a time window could correspond to scenes in a movie, turns in a conversation, or other forms of natural temporal delineation within a message or conversation. One could also set the temporal window to the resolution of an associated content analysis, matching the temporal resolution of the neural data with the temporal resolution of the content-analytic data (see e.g., Weber, 2008). 
More fundamentally, there exists an ongoing debate in the literature as to the extent to which dynamic fluctuations in connectivity are attributable to nuisance variables like head motion (Laumann et al., 2017; Shine \& Poldrack, 2018), arousal (Tagliazucchi \& Laufs, 2014), or natural variability associated with sampling error (Hindriks et al., 2016). Despite this, accumulating evidence provides support for the existence and replicability of dynamic functional connectivity measures (Abrol et al., 2017) and for their close correspondence with a wide range of behaviors (Bassett et al., 2011, 2015; Baum et al., 2017; Cole et al., 2014; Gonzalez-Castillo et al., 2015). This evidence emphasizes the role of behavior in observing and interpreting dynamic fluctuations in connectivity (Shine \& Poldrack, 2018) and highlights the importance of reporting analytic decisions made throughout the processing pipeline.

\subsection{Thresholding}

All of the methods above produce a network that is fully connected, meaning that every node in the network has an edge with every other node. Fully connected graphs introduce numerous computational complexities to network analytic measures. Furthermore, mounting evidence suggests that low correlations between distant nodes are disproportionately likely to be the result of respiration and motion artifacts (Power et al., 2012; van den Heuvel \& Fornito, 2014). As such, many network models of the brain assume sparse connectivity, meaning that every node in the network is only connected to a small proportion of other nodes at any given point in time (Sporns, 2010). As such, network neuroscience studies commonly employ sparsification techniques wherein only a subset of edges in the network are maintained in the final analysis. In order to sparsify a brain network, researchers most often rely on thresholding methods, winnowing away weak or inconsistent edges in the graph while maintaining strong or consistent edges. There are two primary approaches to thresholding employed in the literature: absolute thresholding and proportional thresholding.

In absolute thresholding, all edges above a certain connection strength are maintained (and usually all set to a value of 1), and all edges below the cutoff are removed (van den Heuvel et al., 2017). Although this approach is simple and widely used, it can introduce confounds in comparative analyses (Garrison et al., 2015). Most notably, this method can lead to differing network densities between studies and between experimental and control groups. This limits researchers' ability to compare networks between individuals or between conditions (Nichols et al., 2017; van Wijk et al., 2010). In contrast, proportional thresholding aims to keep the density of connections fixed across individuals and trials. In this method, connections are ranked from strongest to weakest, and a certain percentage of the weakest edges are discarded. This approach has also been quite widely used (Achard \& Bullmore, 2007; Bassett et al., 2009; van den Heuvel et al., 2008) and is relatively computationally simple.

In recent years, thresholding approaches have been criticized for their arbitrariness and for the fact that they binarize inherently continuous data (Bassett et al., 2011; Bassett \& Bullmore, 2017; Tooley et al., 2020). Both absolute and proportional thresholding have been shown to introduce difficulties in comparing brain networks across groups-especially when overall network density may be a salient difference between the two groups (van den Heuvel et al., 2017). Furthermore, mounting evidence suggests that network measures are more robust in graphs that maintain edge weights than in thresholded graphs (Good et al., 2010) and that thresholding may artificially introduce complexity even in relatively simple graphs (Cantwell et al., 2019). As such, it is likely advisable to avoid thresholding unless it is strictly computationally necessary. If thresholding is required, it is perhaps advisable to set multiple levels of thresholding for a particular analysis, comparing the results across thresholds. As with other network construction steps reviewed here, it is imperative that a researcher employ (and report) their network thresholding decisions in light of precedent set by other studies in the topic area. 


\subsection{Statistically Comparing Brain Networks}

Much can be gained from approaches that compare global network measures (such as centrality, average path length, or clustering coefficients) in certain groups or task conditions. This approach requires nothing more than standard hypothesis testing methods and requires the same statistical assumptions as are common in other domains (e.g., normality, homogeneity of variance, appropriate sample size). Often, though, a question of interest requires that statistical tests be performed for smaller subunits of a network (such as individual nodes or clusters). In this case, statistical inference using network models requires comparing a particular unit in an ensemble of observed networks with a matched unit in an ensemble of null models (Fornito et al., 2016; Zalesky et al., 2010). These analyses are complicated by the fact that the null distribution of a brain network adjacency matrix is unknown (Zalesky et al., 2012). As such, null networks must be generated using an algorithm that constructs a network matching the observed network on key characteristics (e.g., number of edges, connectivity patterns) while scrambling characteristics that have to do with the question of interest.

Null networks can be created using random rewiring algorithms (Maslov \& Sneppen, 2002). These approaches randomly rearrange all edges in the network, effectively destroying the connectivity patterns present in the network while maintaining the same number of nodes and edges. Although relatively widely used, this method is not without its issues. Most notably, random rewiring approaches destroy both the intrinsic topological structure of the brain network as well as the network structure within any given time window (Zalesky et al., 2012). Often, a researcher is interested in either the structure of the network across the whole task or how the network evolves during the task. Since these two forms of connectivity are tightly correlated with one another (Cole et al., 2014), the fact that random rewiring creates a null model that destroys both of these characteristics at once makes isolating the overall network structure from the structure of the network within any given time window impossible.

One prominent approach that preserves the transitive structure of the correlation matrix is the Hirschberger-Qi-Steuer (H-Q-S) algorithm (Hirschberger et al., 2007). This algorithm randomly generates networks that are matched to the distribution of covariances observed in the test network. A brute force version of the H-Q-S algorithm is also widely used. This approach, although slower (i.e., more computationally expensive), is designed to create a more accurately matched set of correlation values in the null network (Zalesky et al., 2012). A final rewiring approach-introduced by Rubinov and Sporns (2011)-rewires edges in a manner that preserves both node degree and edge weights, reassigning edges based on an ordered list of node degrees and edge weights. A common approach that does not require rewiring the network is to randomize the time series data itself rather than the connections between nodes. In this approach, the time series at each node is subjected to a Fourier transform, which transforms the underlying time-series into a set of harmonic frequencies (periodogram or power spectrum). After this step, the phases of these frequencies are scrambled and subjected to an inverse transform (from the frequency domain back to the time domain). This preserves critical properties of the time series (like the autocorrelation function, power spectrum, etc.; Breakspear et al., 2004).

After constructing an ensemble of null networks, a researcher can conduct statistical tests for each element of interest. This yields a test statistic and a $p$-value for each individual element. The resulting set of statistics is often called a statistical parametric network (Ginestet \& Simmons, 2011). Once the statistical parametric network is acquired, normal considerations regarding the familywise error rate (FWER) must be considered. For most networks, familiar FWER-controlling methods-such as Bonferroni correction or controlling for the false discovery rate (FDR; Benjamini \& Hochberg, 1995) - can be used. Many other methods for controlling the FWER have been proposed within the literature, including a nonparametric approach known as the network-based statistic (Zalesky et al., 2010). In this approach, groups of topologically adjacent points are clustered together, and the FWER is controlled in relation to the clusters rather than individual points. This approach exploits the topological characteristics of brain networks in 
order to maximize power while still taking the FWER into account. In this sense, it is quite similar to clustering approaches designed for making inferences over statistical parametric maps commonly employed in neuroimaging (Bullmore et al., 1999; Nichols \& Holmes, 2002).

\section{Discussion}

Herein, we have outlined a network neuroscience approach to analyzing brain imaging data. First, we introduced a number of communication-relevant research domains in which network neuroscience approaches may be especially useful for building theory and for explicating the neural underpinnings of communication processes. We then discussed a selection of tools and techniques for preprocessing brain imaging data for use in network analytic methods. Next, we discussed the considerations involved in precisely defining nodes and edges in the network. Following this, we highlighted extant methods for creating dynamic networks that can account for the multiple temporal scales at which a network may evolve during a communication task. Finally, we introduced procedures for statistically analyzing brain networks and for creating valid null models that respect the intrinsic and task-evoked structure of networks of interest.

As with other fMRI measures (Weber, 2015), the potential boon of dynamic network neuroscience for communication research comes with a few caveats. Most notably, many concepts in communication research (such as "presence" or "persuasion") are often multidimensional amalgamations of more wellunderstood processes. In a similar fashion, network models of the brain are also multidimensional, and are difficult to distill into their constitutive parts. Fitting high-dimensional network models to highdimensional theoretical phenomena is at risk of being sidelined by the "curse of dimensionality" (Bellman, 1961), in which patterns observed in high-dimensional spaces do not meaningfully translate into lowdimensional representations. Studies of the dynamic networks underlying communication processes will undeniably benefit from theoretical legwork aimed at clarifying and distilling communication phenomena into component processes that may be investigated using neural data.

A network is, by definition, a "ruthless abstraction" of the real world (Fornito et al., 2016). As such, brain network analysis, perhaps more than any neuroimaging method developed thus far, requires researchers to make numerous analytic decisions to coax their data into a form that is amenable to analysis using traditional statistical tests. It is perhaps fitting to describe network neuroscience as a "garden of forking paths" (Gelman \& Loken, 2014) in which any decision made in the preprocessing and analysis pipeline can influence the outcomes of statistical tests as well as the interpretation of those outcomes. It is quite possible that a well-intentioned researcher can observe a promising pattern of interest in their data only to discover that this pattern is, in fact, an artifact of preprocessing, node definition, thresholding strategy, or other decision made in the analytic pipeline. This fact has led to multiple calls for the development of best practices in conducting and reporting brain network studies (Dubois \& Adolphs, 2016; Gilmore et al., 2017; Nichols et al., 2017). It is critical that communication scholars who wish to leverage network neuroscience methods stay abreast of developing tools and analytic standards and report any analytic decision made during network construction and analysis.

Novel methods for data collection/analysis allow researchers to push the limits of existing theories and facilitate the development of new perspectives (Greenwald, 2012). This method-theory synergy approach has been outlined within the context of communication neuroscience by Weber and colleagues (2015; 2018). Emerging network neuroscience methods, including edge-centric connectivity analyses (Faskowitz et al., 2020), individual-specific functional mapping (Gratton et al., 2019), and network-based predictive modeling (Rosenberg et al., 2020) will undeniably create new opportunities for understanding. Although network science is far from a new concept in communication research (Monge \& Contractor, 2003), the recent debut of network neuroscience approaches in communication has created new opportunities for 
advancing our understanding of the neural precursors, mediators, and outcomes of communication (Schmälzle \& Meshi, 2020).

\section{References}

Abraham, A., Pedregosa, F., Eickenberg, M., Gervais, P., Mueller, A., Kossaifi, J., Gramfort, A., Thirion, B., \& Varoquaux, G. (2014). Machine learning for neuroimaging with scikit-learn. Frontiers in Neuroinformatics, 8(14), 1-10. https://doi.org/10.3389/fninf.2014.00014

Abrol, A., Damaraju, E., Miller, R. L., Stephen, J. M., Claus, E. D., Mayer, A. R., \& Calhoun, V. D. (2017). Replicability of time-varying connectivity patterns in large resting state fMRI samples. Neurolmage, 163, 160-176. https://doi.org/10.1016/j.neuroimage.2017.09.020

Achard, S., \& Bullmore, E. (2007). Efficiency and cost of economical brain functional networks. PLoS Computational Biology, 3(2), e17. https://doi.org/10.1371/journal.pcbi.0030017

Afyouni, S., Smith, S. M., \& Nichols, T. E. (2019). Effective degrees of freedom of the Pearson's correlation coefficient under autocorrelation. Neurolmage, 199, 609-625.

https://doi.org/10.1016/j.neuroimage.2019.05.011

Alakörkkö, T., Saarimäki, H., Glerean, E., Saramäki, J., \& Korhonen, O. (2017). Effects of spatial smoothing on functional brain networks. European Journal of Neuroscience, 46(9), 2471-2480. https://doi.org/10.1111/ejn.13717

Aly, M., Chen, J., Turk-Browne, N. B., \& Hasson, U. (2018). Learning naturalistic temporal structure in the posterior medial network. Journal of Cognitive Neuroscience, 30(9), 1345-1365. https://doi.org/10.1162/jocn a 01308

Andric, M., Goldin-Meadow, S., Small, S. L., \& Hasson, U. (2016). Repeated movie viewings produce similar local activity patterns but different network configurations. Neurolmage, 142, 613-627. https://doi.org/10.1016/j.neuroimage.2016.07.061

Anzellotti, S., \& Coutanche, M. N. (2018). Beyond functional connectivity: Investigating networks of multivariate representations. Trends in Cognitive Sciences, 22(3), 258-269. https://doi.org/10.1016/j.tics.2017.12.002

Arslan, S., Ktena, S. I., Makropoulos, A., Robinson, E. C., Rueckert, D., \& Parisot, S. (2018). Human brain mapping: A systematic comparison of parcellation methods for the human cerebral cortex. Neurolmage, 170, 5-30. https://doi.org/10.1016/j.neuroimage.2017.04.014

Baek, E. C., Scholz, C., O'Donnell, M. B., \& Falk, E. B. (2017). The value of sharing information: A neural account of information transmission. Psychological Science, 28(7), 851-861. https://doi.org/10.1177/0956797617695073

Baek, E. C., Porter, M. A., \& Parkinson, C. (2020). Social network analysis for social neuroscientists. Social Cognitive and Affective Neuroscience. Published online ahead of print. https://doi.org/10.1093/scan/nsaa069

Bassett, D. S., \& Bullmore, E. T. (2017). Small-world brain networks revisited. The Neuroscientist, 23(5), 499-516. https://doi.org/10.1177/1073858416667720

Bassett, D. S., Bullmore, E. T., Meyer-Lindenberg, A., Apud, J. A., Weinberger, D. R., \& Coppola, R. (2009). Cognitive fitness of cost-efficient brain functional networks. Proceedings of the National Academy of Sciences, 106(28), 11747-11752. https://doi.org/10.1073/pnas.0903641106

Bassett, D. S., \& Gazzaniga, M. S. (2011). Understanding complexity in the human brain. Trends in Cognitive Sciences, 15(5), 200-209. https://doi.org/10.1016/j.tics.2011.03.006

Bassett, D. S., \& Sporns, O. (2017). Network neuroscience. Nature Neuroscience, 20(3), 353-364. https://doi.org/10.1038/nn.4502

Bassett, D. S., Wymbs, N. F., Porter, M. A., Mucha, P. J., Carlson, J. M., \& Grafton, S. T. (2011). Dynamic reconfiguration of human brain networks during learning. Proceedings of the National Academy of Sciences, 108(18), 7641-7646. https://doi.org/10.1073/pnas.1018985108

Bassett, D. S., Xia, C. H., \& Satterthwaite, T. D. (2018). Understanding the emergence of neuropsychiatric disorders with network neuroscience. Biological Psychiatry: Cognitive Neuroscience and Neuroimaging, 3(9), 742-753. https://doi.org/10.1016/j.bpsc.2018.03.015

Bassett, D. S., Yang, M., Wymbs, N. F., \& Grafton, S. T. (2015). Learning-induced autonomy of sensorimotor systems. Nature Neuroscience, 18(5), 744-751. https://doi.org/10.1038/nn.3993 
Bassett, D. S., Zurn, P., \& Gold, J. I. (2018). On the nature and use of models in network neuroscience. Nature Reviews Neuroscience, 19(9), 566-578. https://doi.org/10.1038/s41583-018-0038-8

Baum, G. L., Ciric, R., Roalf, D. R., Betzel, R. F., Moore, T. M., Shinohara, R. T., Kahn, A. E., Vandekar, S. N., Rupert, P. E., Quarmley, M., Cook, P. A., Elliott, M. A., Ruparel, K., Gur, R. E., Gur, R. C., Bassett, D. S., \& Satterthwaite, T. D. (2017). Modular segregation of structural brain networks supports the development of executive function in youth. Current Biology, 27(11), 1561-1572.e8. https://doi.org/10.1016/j.cub.2017.04.051

Bayer, J. B., O'Donnell, M. B., Cascio, C. N., \& Falk, E. B. (2018). Brain sensitivity to exclusion is associated with core network closure. Scientific Reports, 8(1), 16037. https://doi.org/10.1038/s41598-018-33624-3

Bellman, R. E. (1961). Adaptive control processes: A guided tour. Princeton University Press.

Benjamini, Y., \& Hochberg, Y. (1995). Controlling the false discovery rate: A practical and powerful approach to multiple testing. Journal of the Royal Statistical Society B, 57(1), 289-300. JSTOR.

Bertolero, M. A., \& Bassett, D. S. (2019). On the nature of explanations offered by network science: A perspective from and for practicing neuroscientists. ArXiv:1911.05031 [q-Bio]. http://arxiv.org/abs/1911.05031

Betzel, R. F., \& Bassett, D. S. (2017). Multi-scale brain networks. Neurolmage, 160, 73-83. https://doi.org/10.1016/j.neuroimage.2016.11.006

Betzel, R. F., Byrge, L., Esfahlani, F. Z., \& Kennedy, D. P. (2019). Temporal fluctuations in the brain's modular architecture during movie-watching. BioRxiv, 750919. https://doi.org/10.1101/750919

Betzel, R. F., Byrge, L., He, Y., Goñi, J., Zuo, X.-N., \& Sporns, O. (2014). Changes in structural and functional connectivity among resting-state networks across the human lifespan. Neurolmage, 102, 345-357. https://doi.org/10.1016/j.neuroimage.2014.07.067

Bickart, K. C., Hollenbeck, M. C., Barrett, L. F., \& Dickerson, B. C. (2012). Intrinsic amygdala-cortical functional connectivity predicts social network size in humans. Journal of Neuroscience, 32(42), 14729-14741. https://doi.org/10.1523/JNEUROSCl.1599-12.2012

Bielczyk, N. Z., Uithol, S., van Mourik, T., Anderson, P., Glennon, J. C., \& Buitelaar, J. K. (2018). Disentangling causal webs in the brain using functional magnetic resonance imaging: A review of current approaches. Network Neuroscience, 3(2), 237-273. https://doi.org/10.1162/netn a 00062

Bottenhorn, K. L., Flannery, J. S., Boeving, E. R., Riedel, M. C., Eickhoff, S. B., Sutherland, M. T., \& Laird, A. R. (2019). Cooperating yet distinct brain networks engaged during naturalistic paradigms: A meta-analysis of functional MRI results. Network Neuroscience, 3(1), 27-48. https://doi.org/10.1162/netn a 00050

Breakspear, M., Brammer, M. J., Bullmore, E. T., Das, P., \& Williams, L. M. (2004). Spatiotemporal wavelet resampling for functional neuroimaging data. Human Brain Mapping, 23(1), 1-25. https://doi.org/10.1002/hbm.20045

Bressler, S. L., \& Menon, V. (2010). Large-scale brain networks in cognition: Emerging methods and principles. Trends in Cognitive Sciences, 14(6), 277-290. https://doi.org/10.1016/j.tics.2010.04.004

Bright, M. G., Tench, C. R., \& Murphy, K. (2017). Potential pitfalls when denoising resting state fMRI data using nuisance regression. Neuroimage, 154, 159-168. https://doi.org/10.1016/j.neuroimage.2016.12.027

Bullmore, E. T., \& Sporns, O. (2009). Complex brain networks: Graph theoretical analysis of structural and functional systems. Nature Reviews Neuroscience, 10(3), 186-198. https://doi.org/10.1038/nrn2575

Bullmore, E. T., Suckling, J., Overmeyer, S., Rabe-Hesketh, S., Taylor, E., \& Brammer, M. J. (1999). Global, voxel, and cluster tests, by theory and permutation, for a difference between two groups of structural MR images of the brain. IEEE Transactions on Medical Imaging, 18(1), 32-42. https://doi.org/10.1109/42.750253

Cáceda, R., James, G. A., Gutman, D. A., \& Kilts, C. D. (2015). Organization of intrinsic functional brain connectivity predicts decisions to reciprocate social behavior. Behavioural Brain Research, 292, 478-483. https://doi.org/10.1016/j.bbr.2015.07.008

Cacioppo, S., Zhou, H., Monteleone, G., Majka, E. A., Quinn, K. A., Ball, A. B., Norman, G. J., Semin, G. R., \& Cacioppo, J. T. (2014). You are in sync with me: Neural correlates of interpersonal synchrony with a partner. Neuroscience, 277, 842-858. https://doi.org/10.1016/j.neuroscience.2014.07.051

Cajal, R. (1911). Histology of the nervous system of man and vertebrates. Oxford University Press.

Calamante, F., Smith, R. E., Liang, X., Zalesky, A., \& Connelly, A. (2017). Track-weighted dynamic functional connectivity (TW-dFC): A new method to study time-resolved functional connectivity. Brain Structure and Function, 222(8), 3761-3774. https://doi.org/10.1007/s00429-017-1431-1 
Calhoun, V. D., Miller, R., Pearlson, G., \& Adalı, T. (2014). The chronnectome: Time-varying connectivity networks as the next frontier in fMRI data discovery. Neuron, 84(2), 262-274.

https://doi.org/10.1016/j.neuron.2014.10.015

Cantwell, G., Liu, Y., Maier, B. F., Schwarze, A. C., Serván, C. A., Snyder, J., \& St-Onge, G. (2019). Thresholding normally distributed data creates complex networks. ArXiv:1902.08278 [Physics].

http://arxiv.org/abs/1902.08278

Cao, M., Wang, J.-H., Dai, Z.-J., Cao, X.-Y., Jiang, L.-L., Fan, F.-M., Song, X.-W., Xia, M.-R., Shu, N., Dong, Q., Milham, M. P., Castellanos, F. X., Zuo, X.-N., \& He, Y. (2014). Topological organization of the human brain functional connectome across the lifespan. Developmental Cognitive Neuroscience, 7, 76-93.

https://doi.org/10.1016/j.dcn.2013.11.004

Chang, C., \& Glover, G. H. (2010). Time-frequency dynamics of resting-state brain connectivity measured with fMRI. Neurolmage, 50(1), 81-98. https://doi.org/10.1016/j.neuroimage.2009.12.011

Choe, A. S., Nebel, M. B., Barber, A. D., Cohen, J. R., Xu, Y., Pekar, J. J., Caffo, B., \& Lindquist, M. A. (2017). Comparing test-retest reliability of dynamic functional connectivity methods. Neurolmage, 158, 155-175. https://doi.org/10.1016/j.neuroimage.2017.07.005

Ciric, R., Wolf, D. H., Power, J. D., Roalf, D. R., Baum, G. L., Ruparel, K., Shinohara, R. T., Elliott, M. A., Eickhoff, S. B., Davatzikos, C., Gur, R. C., Gur, R. E., Bassett, D. S., \& Satterthwaite, T. D. (2017). Benchmarking of participant-level confound regression strategies for the control of motion artifact in studies of functional connectivity. Neurolmage, 154, 174-187. https://doi.org/10.1016/j.neuroimage.2017.03.020

Cole, M. W., Bassett, D. S., Power, J. D., Braver, T. S., \& Petersen, S. E. (2014). Intrinsic and task-evoked network architectures of the human brain. Neuron, 83(1), 238-251. https://doi.org/10.1016/j.neuron.2014.05.014

Cooper, N., Bassett, D. S., \& Falk, E. B. (2017). Coherent activity between brain regions that code for value is linked to the malleability of human behavior. Scientific Reports, 7(1). https://doi.org/10.1038/srep43250

Cooper, N., Garcia, J. O., Tompson, S. H., O’Donnell, M. B., Falk, E. B., \& Vettel, J. M. (2018). Time-evolving dynamics in brain networks forecast responses to health messaging. Network Neuroscience, 3(1), 138-156. https://doi.org/10.1162/netn a 00058

Craddock, R. C., James, G. A., Holtzheimer, P. E., Hu, X. P., \& Mayberg, H. S. (2012). A whole brain fMRI atlas generated via spatially constrained spectral clustering. Human Brain Mapping, 33(8), 1914-1928. https://doi.org/10.1002/hbm.21333

Craig, R. T. (1993). Why Are There So Many Communication Theories? Journal of Communication, 43(3), $26-33$. https://doi.org/10.1111/j.1460-2466.1993.tb01273.x

Csikszentmihalyi, M. (1990). Flow: The psychology of optimal performance. Harper and Row.

de Manzano, Ö., Cervenka, S., Jucaite, A., Hellenäs, O., Farde, L., \& Ullén, F. (2013). Individual differences in the proneness to have flow experiences are linked to dopamine D2-receptor availability in the dorsal striatum. Neurolmage, 67, 1-6. https://doi.org/10.1016/j.neuroimage.2012.10.072

Di Domenico, S. I., \& Ryan, R. M. (2017). The emerging neuroscience of intrinsic motivation: A new frontier in selfdetermination research. Frontiers in Human Neuroscience, 11(145), 1-14. https://doi.org/10.3389/fnhum.2017.00145

Dubois, J., \& Adolphs, R. (2016). Building a science of individual differences from fMRI. Trends in Cognitive Sciences, 20(6), 425-443. https://doi.org/10.1016/j.tics.2016.03.014

Eichler, M. (2013). Causal inference with multiple time series: Principles and problems. Philosophical Transactions of the Royal Society A: Mathematical, Physical and Engineering Sciences, 371(1997), 20110613. https://doi.org/10.1098/rsta.2011.0613

Eickhoff, S. B., Constable, R. T., \& Yeo, B. T. T. (2018). Topographic organization of the cerebral cortex and brain cartography. Neurolmage, 170, 332-347. https://doi.org/10.1016/j.neuroimage.2017.02.018

Elliott, M. L., Knodt, A. R., Cooke, M., Kim, M. J., Melzer, T. R., Keenan, R., Ireland, D., Ramrakha, S., Poulton, R., Caspi, A., Moffitt, T. E., \& Hariri, A. R. (2019). General functional connectivity: Shared features of resting-state and task fMRI drive reliable and heritable individual differences in functional brain networks. Neurolmage, 189, 516-532. https://doi.org/10.1016/j.neuroimage.2019.01.068

Elton, A., Alcauter, S., \& Gao, W. (2014). Network connectivity abnormality profile supports a categoricaldimensional hybrid model of ADHD. Human Brain Mapping, 35(9), 4531-4543. 
https://doi.org/10.1002/hbm.22492

Esteban, O., Markiewicz, C. J., Blair, R. W., Moodie, C. A., Isik, A. I., Erramuzpe, A., Kent, J. D., Goncalves, M., DuPre, E., Snyder, M., Oya, H., Ghosh, S. S., Wright, J., Durnez, J., Poldrack, R. A., \& Gorgolewski, K. J. (2019). fMRIPrep: A robust preprocessing pipeline for functional MRI. Nature Methods, 16(1), 111.

https://doi.org/10.1038/s41592-018-0235-4

Falk, E. B. (2012). Can neuroscience advance our understanding of core questions in Communication Studies? An overview of Communication Neuroscience. In S. Jones (Ed.), Communication @ The Center. Communication@ the Center.

Falk, E. B., Berkman, E. T., Mann, T., Harrison, B., \& Lieberman, M. D. (2010). Predicting persuasion-induced behavior change from the brain. The Journal of Neuroscience, 30(25), 8421-8424.

Falk, E. B., Rameson, L., Berkman, E. T., \& Liao, B. (2010). The neural correlates of persuasion: A common network across cultures and media. Journal of Cognitive Neuroscience, 22(11), 2447-2459.

Falk, E. B., Spunt, R. P., \& Lieberman, M. D. (2012). Ascribing beliefs to ingroup and outgroup political candidates: Neural correlates of perspective-taking, issue importance and days until the election. Philosophical Transactions of the Royal Society B: Biological Sciences, 367(1589), 731-743.

https://doi.org/10.1098/rstb.2011.0302

Faskowitz, J., Esfahlani, F. Z., Jo, Y., Sporns, O., \& Betzel, R. F. (2020). Edge-centric functional network representations of human cerebral cortex reveal overlapping system-level architecture. Nature Neuroscience, 23(12), 1644-1654. https://doi.org/10.1038/s41593-020-00719-y

Finn, E. S., Scheinost, D., Finn, D. M., Shen, X., Papademetris, X., \& Constable, R. T. (2017). Can brain state be manipulated to emphasize individual differences in functional connectivity? Neurolmage, 160, 140-151. https://doi.org/10.1016/j.neuroimage.2017.03.064

Fisher, J. T., Hopp, F. R., \& Weber, R. (2019a). Disentangling the roles of reward and process type on resource allocation in an interactive task. Paper Presented at the 69th Annual Conference of the International Communication Association.

Fisher, J. T., Hopp, F. R., \& Weber, R. (2019b). Modality-specific effects of perceptual load in multimedia processing. Media \& Communication, 7(4). https://doi.org/10.33767/osf.io/cz2pj

Fisher, J. T., Huskey, R., Keene, J. R., \& Weber, R. (2018). The limited capacity model of motivated mediated message processing: Looking to the future. Annals of the International Communication Association, 42(4), 291-315. https://doi.org/10.1080/23808985.2018.1534551

Fornito, A., Zalesky, A., \& Breakspear, M. (2013). Graph analysis of the human connectome: Promise, progress, and pitfalls. Neurolmage, 80, 426-444. https://doi.org/10.1016/j.neuroimage.2013.04.087

Fornito, A., Zalesky, A., \& Bullmore, E. (2016). Fundamentals of brain network analysis. Academic Press.

Frith, C. D., \& Frith, U. (2006). The neural basis of mentalizing. Neuron, 50(4), 531-534. https://doi.org/10.1016/j.neuron.2006.05.001

Garrison, K. A., Scheinost, D., Finn, E. S., Shen, X., \& Constable, R. T. (2015). The (in)stability of functional brain network measures across thresholds. Neurolmage, 118, 651-661.

https://doi.org/10.1016/j.neuroimage.2015.05.046

Gelman, A., \& Loken, E. (2014). The statistical crisis in science. American Scientist, 102(6), 460-465.

Gilmore, R. O., Diaz, M. T., Wyble, B. A., \& Yarkoni, T. (2017). Progress toward openness, transparency, and reproducibility in cognitive neuroscience. Annals of the New York Academy of Sciences, 1396(1), 5-18. https://doi.org/10.1111/nyas.13325

Ginestet, C. E., \& Simmons, A. (2011). Statistical parametric network analysis of functional connectivity dynamics during a working memory task. Neurolmage, 55(2), 688-704. https://doi.org/10.1016/j.neuroimage.2010.11.030

Glasser, M. F., Coalson, T. S., Robinson, E. C., Hacker, C. D., Harwell, J., Yacoub, E., Ugurbil, K., Andersson, J., Beckmann, C. F., Jenkinson, M., Smith, S. M., \& Van Essen, D. C. (2016). A multi-modal parcellation of human cerebral cortex. Nature, 536(7615), 171-178. https://doi.org/10.1038/nature18933

Gonzalez-Castillo, J., Hoy, C. W., Handwerker, D. A., Robinson, M. E., Buchanan, L. C., Saad, Z. S., \& Bandettini, P. A. (2015). Tracking ongoing cognition in individuals using brief, whole-brain functional connectivity patterns. Proceedings of the National Academy of Sciences, 112(28), 8762-8767. 
https://doi.org/10.1073/pnas.1501242112

Good, B. H., de Montjoye, Y.-A., \& Clauset, A. (2010). Performance of modularity maximization in practical contexts. Physical Review E, 81(4), 046106. https://doi.org/10.1103/PhysRevE.81.046106

Gratton, C., Laumann, T. O., Nielsen, A. N., Greene, D. J., Gordon, E. M., Gilmore, A. W., Nelson, S. M., Coalson, R. S., Snyder, A. Z., Schlaggar, B. L., Dosenbach, N. U. F., \& Petersen, S. E. (2018). Functional brain networks are dominated by stable group and individual factors, not cognitive or daily variation. Neuron, 98(2), 439-452.e5. https://doi.org/10.1016/j.neuron.2018.03.035

Gratton, C., Kraus, B. T., Greene, D. J., Gordon, E. M., Laumann, T. O., Nelson, S. M., Dosenbach, N. U. F., \& Petersen, S. E. (2019). Defining individual-specific functional neuroanatomy for precision psychiatry. Biological Psychiatry. Published online ahead of print. https://doi.org/10.1016/j.biopsych.2019.10.026

Greenwald, A. G. (2012). There is nothing so theoretical as a good method. Perspectives on Psychological Science, 7(2), 99-108. https://doi.org/10.1177/1745691611434210

Harris, D. J., Vine, S. J., \& Wilson, M. R. (2017). Neurocognitive mechanisms of the flow state. In M. R. Wilson, V. Walsh, \& B. Parkin (Eds.), Progress in Brain Research (Vol. 234, pp. 221-243). Elsevier. https://doi.org/10.1016/bs.pbr.2017.06.012

Hasson, U., Ghazanfar, A. A., Galantucci, B., Garrod, S., \& Keysers, C. (2012). Brain-to-brain coupling: A mechanism for creating and sharing a social world. Trends in Cognitive Sciences, 16(2), 114-121. https://doi.org/10.1016/j.tics.2011.12.007

Hasson, U., Landesman, O., Knappmeyer, B., Vallines, I., Rubin, N., \& Heeger, D. J. (2008). Neurocinematics: The neuroscience of film. Projections, 2(1), 1-26. https://doi.org/10.3167/proj.2008.020102

Hayasaka, S., \& Laurienti, P. J. (2010). Comparison of characteristics between region-and voxel-based network analyses in resting-state fMRI data. Neurolmage, 50(2), 499-508. https://doi.org/10.1016/j.neuroimage.2009.12.051

Hindriks, R., Adhikari, M. H., Murayama, Y., Ganzetti, M., Mantini, D., Logothetis, N. K., \& Deco, G. (2016). Can sliding-window correlations reveal dynamic functional connectivity in resting-state fMRI? Neurolmage, 127, 242-256. https://doi.org/10.1016/j.neuroimage.2015.11.055

Hirschberger, M., Qi, Y., \& Steuer, R. E. (2007). Randomly generating portfolio-selection covariance matrices with specified distributional characteristics. European Journal of Operational Research, 177(3), 1610-1625. https://doi.org/10.1016/j.ejor.2005.10.014

Honari, H., Choe, A. S., Pekar, J. J., \& Lindquist, M. A. (2019). Investigating the impact of autocorrelation on timevarying connectivity. Neurolmage, 197, 37-48. https://doi.org/10.1016/j.neuroimage.2019.04.042

Hopp, F. R., \& Weber, R. (in press). The state-of-the-art and the future of functional magnetic resonance imaging in communication research. In The handbook of communication science and biology. Routledge.

Horien, C., Shen, X., Scheinost, D., \& Constable, R. T. (2019). The individual functional connectome is unique and stable over months to years. Neurolmage, 189, 676-687. https://doi.org/10.1016/j. neuroimage.2019.02.002

Huskey, R. (2016). Beyond blobology: Using psychophysiological interaction analyses to investigate the neural basis of human communication phenomena. In S. Kubitschko \& A. Kaun (Eds.), Innovative methods in media and communication research (pp. 123-138). Palgrave Macmillan.

Huskey, R., Craighead, B., Miller, M. B., \& Weber, R. (2018). Does intrinsic reward motivate cognitive control? A naturalistic-fMRI study based on the synchronization theory of flow. Cognitive, Affective, \& Behavioral Neuroscience, 18(5), 902-924. https://doi.org/10.3758/s13415-018-0612-6

Huskey, R., Mangus, J. M., Turner, B. O., \& Weber, R. (2017). The persuasion network is modulated by drug-use risk and predicts anti-drug message effectiveness. Social Cognitive and Affective Neuroscience, 12(12), 19021915. https://doi.org/10.1093/scan/nsx126

Huskey, R., Wilcox, S., \& Weber, R. (2018). Network neuroscience reveals distinct neuromarkers of flow during media use. Journal of Communication, 68(5), 872-895.

Hutchison, R. M., Womelsdorf, T., Allen, E. A., Bandettini, P. A., Calhoun, V. D., Corbetta, M., Della Penna, S., Duyn, J. H., Glover, G. H., Gonzalez-Castillo, J., Handwerker, D. A., Keilholz, S., Kiviniemi, V., Leopold, D. A., de Pasquale, F., Sporns, O., Walter, M., \& Chang, C. (2013). Dynamic functional connectivity: Promise, issues, and interpretations. Neurolmage, 80, 360-378. https://doi.org/10.1016/j.neuroimage.2013.05.079

Jalili, M. (2016). Functional brain networks: Does the choice of dependency estimator and binarization method 
matter? Scientific Reports, 6, 29780. https://doi.org/10.1038/srep29780

Jo, H. J., Saad, Z. S., Simmons, W. K., Milbury, L. A., \& Cox, R. W. (2010). Mapping sources of correlation in resting state fMRI, with artifact detection and removal. Neurolmage, 52(2), 571-582.

https://doi.org/10.1016/j.neuroimage.2010.04.246

Johansen-Berg, H., \& Behrens, T. E. J. (2006). Just pretty pictures? What diffusion tractography can add in clinical neuroscience. Current Opinion in Neurology, 19(4), 379-385.

https://doi.org/10.1097/01.wc0.0000236618.82086.01

Jolly, E., \& Chang, L. J. (2019). The flatland fallacy: Moving beyond low-dimensional thinking. Topics in Cognitive Science, 11(2), 433-454. https://doi.org/10.1111/tops.12404

Klasen, M., Zvyagintsev, M., Schwenzer, M., Mathiak, K. A., Sarkheil, P., Weber, R., \& Mathiak, K. (2013). Quetiapine modulates functional connectivity in brain aggression networks. Neurolmage, 75, 20-26. https://doi.org/10.1016/j.neuroimage.2013.02.053

Kong, R., Li, J., Orban, C., Sabuncu, M. R., Liu, H., Schaefer, A., Sun, N., Zuo, X.-N., Holmes, A. J., Eickhoff, S. B., \& Yeo, B. T. T. (2019). Spatial topography of individual-specific cortical networks predicts human cognition, personality, and emotion. Cerebral Cortex, 29(6), 2533-2551. https://doi.org/10.1093/cercor/bhy123

Konrad, K., \& Eickhoff, S. B. (2010). Is the ADHD brain wired differently? A review on structural and functional connectivity in attention deficit hyperactivity disorder. Human Brain Mapping, 31(6), 904-916. https://doi.org/10.1002/hbm.21058

Lang, A. (2000). The limited capacity model of mediated message processing. Journal of Communication, 50(1), 46-70. https://doi.org/10.1111/j.1460-2466.2000.tb02833.x

Laumann, T. O., Snyder, A. Z., Mitra, A., Gordon, E. M., Gratton, C., Adeyemo, B., Gilmore, A. W., Nelson, S. M., Berg, J. J., Greene, D. J., McCarthy, J. E., Tagliazucchi, E., Laufs, H., Schlaggar, B. L., Dosenbach, N. U. F., \& Petersen, S. E. (2017). On the stability of BOLD fMRI correlations. Cerebral Cortex, 27(10), 4719-4732. https://doi.org/10.1093/cercor/bhw265

Leonardi, N., \& Van De Ville, D. (2015). On spurious and real fluctuations of dynamic functional connectivity during rest. Neurolmage, 104, 430-436. https://doi.org/10.1016/j.neuroimage.2014.09.007

Liégeois, R., Laumann, T. O., Snyder, A. Z., Zhou, J., \& Yeo, B. T. T. (2017). Interpreting temporal fluctuations in resting-state functional connectivity MRI. Neurolmage, 163, 437-455. https://doi.org/10.1016/j.neuroimage.2017.09.012

Loewe, K., Donohue, S. E., Schoenfeld, M. A., Kruse, R., \& Borgelt, C. (2016). Memory-efficient analysis of dense functional connectomes. Frontiers in Neuroinformatics, 10. https://doi.org/10.3389/fninf.2016.00050

Lund, T. E., Madsen, K. H., Sidaros, K., Luo, W.-L., \& Nichols, T. E. (2006). Non-white noise in fMRI: Does modelling have an impact? Neurolmage, 29(1), 54-66. https://doi.org/10.1016/j.neuroimage.2005.07.005

Lydon-Staley, D. M., Ciric, R., Satterthwaite, T. D., \& Bassett, D. S. (2019). Evaluation of confound regression strategies for the mitigation of micromovement artifact in studies of dynamic resting-state functional connectivity and multilayer network modularity. Network Neuroscience, 3(2), 427-454. https://doi.org/10.1162/netn a 00071

Maslov, S., \& Sneppen, K. (2002). Specificity and stability in topology of protein networks. Science, 296(5569), 910-913. https://doi.org/10.1126/science.1065103

Mathiak, K., \& Weber, R. (2006). Toward brain correlates of natural behavior: FMRI during violent video games. Human Brain Mapping, 27(12), 948-956. https://doi.org/10.1002/hbm.20234

Medaglia, J. D., Lynall, M.-E., \& Bassett, D. S. (2015). Cognitive network neuroscience. Journal of Cognitive Neuroscience, 27(8), 1471-1491. https://doi.org/10.1162/jocn a 00810

Meshi, D., Mamerow, L., Kirilina, E., Morawetz, C., Margulies, D. S., \& Heekeren, H. R. (2016). Sharing self-related information is associated with intrinsic functional connectivity of cortical midline brain regions. Scientific Reports, 6, 22491. https://doi.org/10.1038/srep22491

Meshi, D., Tamir, D. I., \& Heekeren, H. R. (2015). The emerging neuroscience of social media. Trends in Cognitive Sciences, 19(12), 771-782. https://doi.org/10.1016/j.tics.2015.09.004

Monge, P. R., \& Contractor, N. (2003). Theories of communication networks. Oxford University Press.

Mucha, P. J., Richardson, T., Macon, K., Porter, M. A., \& Onnela, J.-P. (2010). Community structure in timedependent, multiscale, and multiplex networks. Science, 328(5980), 876-878. 
https://doi.org/10.1126/science.1184819

Nastase, S. A., Gazzola, V., Hasson, U., \& Keysers, C. (2019). Measuring shared responses across subjects using intersubject correlation. Social Cognitive and Affective Neuroscience, 14(6), 667-685.

https://doi.org/10.1093/scan/nsz037

Nichols, T. E., Das, S., Eickhoff, S. B., Evans, A. C., Glatard, T., Hanke, M., Kriegeskorte, N., Milham, M. P., Poldrack, R. A., Poline, J.-B., Proal, E., \& Thirion, B. (2017). Best practices in data analysis and sharing in neuroimaging using MRI. Nature Neuroscience, 20(3), 299-303.

Nichols, T. E., \& Holmes, A. P. (2002). Nonparametric permutation tests for functional neuroimaging: A primer with examples. Human Brain Mapping, 15(1), 1-25. https://doi.org/10.1002/hbm.1058

O’Donnell, M. B., Bayer, J. B., Cascio, C. N., \& Falk, E. B. (2017). Neural bases of recommendations differ according to social network structure. Social Cognitive and Affective Neuroscience, 12(1), 61-69. https://doi.org/10.1093/scan/nsw158

Parkinson, C., Kleinbaum, A. M., \& Wheatley, T. (2018). Similar neural responses predict friendship. Nature Communications, 9(1), 332. https://doi.org/10.1038/s41467-017-02722-7

Pessoa, L. (2017). A network model of the emotional brain. Trends in Cognitive Sciences, 21(5), 357-371. https://doi.org/10.1016/j.tics.2017.03.002

Power, J. D., Barnes, K. A., Snyder, A. Z., Schlaggar, B. L., \& Petersen, S. E. (2012). Spurious but systematic correlations in functional connectivity MRI networks arise from subject motion. Neurolmage, 59(3), 21422154. https://doi.org/10.1016/i.neuroimage.2011.10.018

Power, J. D., Cohen, A. L., Nelson, S. M., Wig, G. S., Barnes, K. A., Church, J. A., Vogel, A. C., Laumann, T. O., Miezin, F. M., Schlaggar, B. L., \& Petersen, S. E. (2011). Functional network organization of the human brain. Neuron, 72(4), 665-678. https://doi.org/10.1016/j.neuron.2011.09.006

Preti, M. G., Bolton, T. A., \& Van De Ville, D. (2017). The dynamic functional connectome: State-of-the-art and perspectives. Neurolmage, 160, 41-54. https://doi.org/10.1016/j.neuroimage.2016.12.061

Rashid, B., Arbabshirani, M. R., Damaraju, E., Cetin, M. S., Miller, R., Pearlson, G. D., \& Calhoun, V. D. (2016). Classification of schizophrenia and bipolar patients using static and dynamic resting-state fMRI brain connectivity. Neurolmage, 134, 645-657. https://doi.org/10.1016/j.neuroimage.2016.04.051

Rathkopf, C. (2018). Network representation and complex systems. Synthese, 195(1), 55-78. https://doi.org/10.1007/s11229-015-0726-0

Regev, M., Simony, E., Lee, K., Tan, K. M., Chen, J., \& Hasson, U. (2018). Propagation of information along the cortical hierarchy as a function of attention while reading and listening to stories. Cerebral Cortex, 1-18. https://doi.org/10.1093/cercor/bhy282

Reineberg, A. E., Andrews-Hanna, J. R., Depue, B. E., Friedman, N. P., \& Banich, M. T. (2015). Resting-state networks predict individual differences in common and specific aspects of executive function. Neurolmage, 104, 69-78. https://doi.org/10.1016/j.neuroimage.2014.09.045

Roebroeck, A., Formisano, E., \& Goebel, R. (2005). Mapping directed influence over the brain using Granger causality and fMRI. Neurolmage, 25(1), 230-242. https://doi.org/10.1016/j. neuroimage.2004.11.017

Rombouts, S. A. R. B., Damoiseaux, J. S., Goekoop, R., Barkhof, F., Scheltens, P., Smith, S. M., \& Beckmann, C. F. (2009). Model-free group analysis shows altered BOLD FMRI networks in dementia. Human Brain Mapping, 30(1), 256-266. https://doi.org/10.1002/hbm.20505

Rosenberg, M. D., Finn, E. S., Scheinost, D., Papademetris, X., Shen, X., Constable, R. T., \& Chun, M. M. (2016). A neuromarker of sustained attention from whole-brain functional connectivity. Nature Neuroscience, 19(1), 165-171. https://doi.org/10.1038/nn.4179

Rosenberg, M. D., Scheinost, D., Greene, A. S., Avery, E. W., Kwon, Y. H., Finn, E. S., Ramani, R., Qiu, M., Constable, R. T., \& Chun, M. M. (2020). Functional connectivity predicts changes in attention over minutes, days, and months. Proceedings of the National Academy of Sciences. 117, 3797-3807. https://doi.org/10.1101/700476

Rubinov, M., \& Sporns, O. (2010). Complex network measures of brain connectivity: Uses and interpretations. Neurolmage, 52(3), 1059-1069. https://doi.org/10.1016/j.neuroimage.2009.10.003

Rubinov, M., \& Sporns, O. (2011). Weight-conserving characterization of complex functional brain networks. Neurolmage, 56(4), 2068-2079. https://doi.org/10.1016/j.neuroimage.2011.03.069

Schilbach, L., Eickhoff, S. B., Rotarska-Jagiela, A., Fink, G. R., \& Vogeley, K. (2008). Minds at rest? Social cognition 
as the default mode of cognizing and its putative relationship to the "default system" of the brain. Consciousness and Cognition, 17(2), 457-467. https://doi.org/10.1016/j.concog.2008.03.013

Schilbach, L., Wohlschlaeger, A. M., Kraemer, N. C., Newen, A., Shah, N. J., Fink, G. R., \& Vogeley, K. (2006). Being with virtual others: Neural correlates of social interaction. Neuropsychologia, 44(5), 718-730.

https://doi.org/10.1016/j.neuropsychologia.2005.07.017

Schmahmann, J. D., Pandya, D. N., Wang, R., Dai, G., D’Arceuil, H. E., de Crespigny, A. J., \& Wedeen, V. J. (2007). Association fibre pathways of the brain: Parallel observations from diffusion spectrum imaging and autoradiography. Brain, 130(3), 630-653. https://doi.org/10.1093/brain/awl359

Schmälzle, R., Häcker, F. E. K., Honey, C. J., \& Hasson, U. (2015). Engaged listeners: Shared neural processing of powerful political speeches. Social Cognitive and Affective Neuroscience, 10(8), 1137-1143. https://doi.org/10.1093/scan/nsu168

Schmälzle, R., \& Meshi, D. (2020). Communication neuroscience: Theory, methodology and experimental approaches. Communication Methods and Measures, $0(0), 1-20$. https://doi.org/10.1080/19312458.2019.1708283

Schmälzle, R., O’Donnell, M. B., Garcia, J. O., Cascio, C. N., Bayer, J., Bassett, D. S., Vettel, J. M., \& Falk, E. B. (2017). Brain connectivity dynamics during social interaction reflect social network structure. Proceedings of the National Academy of Sciences, 114(20), 5153-5158. https://doi.org/10.1073/pnas.1616130114

Scholz, C., Baek, E. C., O’Donnell, M. B., Kim, H. S., Cappella, J. N., \& Falk, E. B. (2017). A neural model of valuation and information virality. Proceedings of the National Academy of Sciences, 114(11), 2881-2886. https://doi.org/10.1073/pnas.1615259114

Scholz, J., Triantafyllou, C., Whitfield-Gabrieli, S., Brown, E. N., \& Saxe, R. (2009). Distinct regions of right temporo-parietal junction are selective for theory of mind and exogenous attention. PLOS ONE, 4(3), e4869. https://doi.org/10.1371/journal.pone.0004869

Schultz, W., Dayan, P., \& Montague, P. R. (1997). A neural substrate of prediction and reward. Science, 275(5306), 1593-1599. https://doi.org/10.1126/science.275.5306.1593

Shakil, S., Lee, C.-H., \& Keilholz, S. D. (2016). Evaluation of sliding window correlation performance for characterizing dynamic functional connectivity and brain states. Neurolmage, 133, 111-128. https://doi.org/10.1016/j.neuroimage.2016.02.074

Shen, X., Papademetris, X., \& Constable, R. T. (2010). Graph-theory based parcellation of functional subunits in the brain from resting-state fMRI data. Neurolmage, 50(3), 1027-1035.

https://doi.org/10.1016/j.neuroimage.2009.12.119

Shen, X., Tokoglu, F., Papademetris, X., \& Constable, R. T. (2013). Groupwise whole-brain parcellation from resting-state fMRI data for network node identification. Neurolmage, 82, 403-415. https://doi.org/10.1016/j.neuroimage.2013.05.081

Shine, J. M., \& Poldrack, R. A. (2018). Principles of dynamic network reconfiguration across diverse brain states. Neurolmage, 180, 396-405. https://doi.org/10.1016/j.neuroimage.2017.08.010

Simony, E., Honey, C. J., Chen, J., Lositsky, O., Yeshurun, Y., Wiesel, A., \& Hasson, U. (2016). Dynamic reconfiguration of the default mode network during narrative comprehension. Nature Communications, 7 , 12141. https://doi.org/10.1038/ncomms12141

Sizemore, A. E., \& Bassett, D. S. (2017). Dynamic graph metrics: Tutorial, toolbox, and tale. Neurolmage, 180, 417-427. https://doi.org/10.1016/j.neuroimage.2017.06.081

Sporns, O. (2010). Networks of the brain. MIT press.

Stephens, G. J., Silbert, L. J., \& Hasson, U. (2010). Speaker-listener neural coupling underlies successful communication. Proceedings of the National Academy of Sciences, 107(32), 14425-14430. https://doi.org/10.1073/pnas.1008662107

Su, J., Shen, H., Zeng, L.-L., Qin, J., Liu, Z., \& Hu, D. (2016). Heredity characteristics of schizophrenia shown by dynamic functional connectivity analysis of resting-state functional MRI scans of unaffected siblings. NeuroReport, 27(11), 843. https://doi.org/10.1097/WNR.0000000000000622

Swanson, L. W., \& Lichtman, J. W. (2016). From Cajal to connectome and beyond. Annual Review of Neuroscience, 39(1), 197-216. https://doi.org/10.1146/annurev-neuro-071714-033954

Tagliazucchi, E., \& Laufs, H. (2014). Decoding wakefulness levels from typical fMRI resting-state data reveals 
reliable drifts between wakefulness and sleep. Neuron, 82(3), 695-708.

https://doi.org/10.1016/j.neuron.2014.03.020

Tompson, S. H., Falk, E. B., O’Donnell, M. B., Cascio, C. N., Bayer, J. B., Vettel, J. M., \& Bassett, D. S. (2018). Response inhibition in adolescents is moderated by brain connectivity and social network structure. BioRxiv, 395038. https://doi.org/10.1101/395038

Tooley, U. A., Mackey, A. P., Ciric, R., Ruparel, K., Moore, T. M., Gur, R. C., Gur, R. E., Satterthwaite, T. D., \& Bassett, D. S. (2020). Associations between neighborhood SES and functional brain network development. Cerebral Cortex, 30(1), 1-19. https://doi.org/10.1093/cercor/bhz066

Turner, B. O., Huskey, R., \& Weber, R. (2018). Charting a future for fMRI in communication science. Communication Methods and Measures, 13(1), 1-18. https://doi.org/10.1080/19312458.2018.1520823

Uğurbil, K. (2016). What is feasible with imaging human brain function and connectivity using functional magnetic resonance imaging. Philosophical Transactions of the Royal Society of London. Series B, Biological Sciences, 371(1705). https://doi.org/10.1098/rstb.2015.0361

Valkenburg, P. M., \& Peter, J. (2013). Five challenges for the future of media-effects research. International Journal of Communication, 7, 197-215.

van den Heuvel, M. P., de Lange, S. C., Zalesky, A., Seguin, C., Yeo, B. T. T., \& Schmidt, R. (2017). Proportional thresholding in resting-state fMRI functional connectivity networks and consequences for patient-control connectome studies: Issues and recommendations. Neurolmage, 152, 437-449.

https://doi.org/10.1016/j.neuroimage.2017.02.005

van den Heuvel, M. P., \& Fornito, A. (2014). Brain networks in schizophrenia. Neuropsychology Review, 24(1), 3248. https://doi.org/10.1007/s11065-014-9248-7.

van den Heuvel, M. P., Stam, C. J., Boersma, M., \& Hulshoff Pol, H. E. (2008). Small-world and scale-free organization of voxel-based resting-state functional connectivity in the human brain. Neurolmage, 43(3), 528-539. https://doi.org/10.1016/j.neuroimage.2008.08.010

Van Dijk, K. R. A., Sabuncu, M. R., \& Buckner, R. L. (2012). The influence of head motion on intrinsic functional connectivity MRI. Neurolmage, 59(1), 431-438. https://doi.org/10.1016/j.neuroimage.2011.07.044

van Wijk, B. C. M., Stam, C. J., \& Daffertshofer, A. (2010). Comparing brain networks of different size and connectivity density using graph theory. PLOS ONE, 5(10), e13701. https://doi.org/10.1371/journal.pone.0013701

Vanderwal, T., Eilbott, J., Finn, E. S., Craddock, R. C., Turnbull, A., \& Castellanos, F. X. (2017). Individual differences in functional connectivity during naturalistic viewing conditions. Neurolmage, 157, 521-530. https://doi.org/10.1016/j.neuroimage.2017.06.027

Wang, J., Ren, Y., Hu, X., Nguyen, V. T., Guo, L., Han, J., \& Guo, C. C. (2017). Test-retest reliability of functional connectivity networks during naturalistic fMRI paradigms. Human Brain Mapping, 38(4), 2226-2241. https://doi.org/10.1002/hbm.23517

Weber, R.. (2008). Connectivity of brain regions during social interactions. Theory-based content analysis of continuous natural stimuli as a paradigm in functional magnetic resonance imaging. RWTH Library.

Weber, R.. (2015). Brain, mind, and media: Neuroscience meets media psychology. Journal of Media Psychology, 27(3), 89-92. https://doi.org/10.1027/1864-1105/a000162

Weber, R., Alicea, B., Huskey, R., \& Mathiak, K. (2018). Network dynamics of attention during a naturalistic behavioral paradigm. Frontiers in Human Neuroscience, 12(182), 1-14. https://doi.org/10.3389/fnhum.2018.00182

Weber, R., Eden, A., Huskey, R., Mangus, J. M., \& Falk, E. (2015). Bridging media psychology and cognitive neuroscience: Challenges and opportunities. Journal of Media Psychology, 27(3), 146-156.

Weber, R., \& Fisher, J. (2020). Advancing the synchronization theory of flow experiences. In K. Floyd \& R. Weber (Eds.), The Routledge Handbook of Communication Science and Biology.

Weber, R., Fisher, J. T., Hopp, F. R., \& Lonergan, C. (2018). Taking messages into the magnet: Method-theory synergy in communication neuroscience. Communication Monographs, 85(1), 81-102. https://doi.org/10.1080/03637751.2017.1395059

Weber, R., Mathiak, K., \& Sherry, J. L. (2008). The neurophysiological perspective in mass communication research. In M. Beatty, J. McCroskey, \& K. Floyd (Eds.), Biological dimensions of communication: Perspectives, 
methods, and research (pp. 43-73). Hampton Press.

Weber, R., Ritterfeld, U., \& Mathiak, K. (2006). Does playing violent video games induce aggression? Empirical evidence of a functional magnetic resonance imaging study. Media Psychology, 8(1), 39-60. https://doi.org/10.1207/S1532785XMEP0801 4

Weber, R., Tamborini, R., Westcott-Baker, A., \& Kantor, B. (2009). Theorizing flow and media enjoyment as cognitive synchronization of attentional and reward networks. Communication Theory, 19(4), 397-422. https://doi.org/10.1111/j.1468-2885.2009.01352.x

Wedeen, V. J., Wang, R. P., Schmahmann, J. D., Benner, T., Tseng, W. Y. I., Dai, G., Pandya, D. N., Hagmann, P., D’Arceuil, H., \& de Crespigny, A. J. (2008). Diffusion spectrum magnetic resonance imaging (DSI) tractography of crossing fibers. Neurolmage, 41(4), 1267-1277. https://doi.org/10.1016/j.neuroimage.2008.03.036

Wheatley, T., Boncz, A., Toni, I., \& Stolk, A. (2019). Beyond the isolated brain: The promise and challenge of interacting minds. Neuron, 103(2), 186-188. https://doi.org/10.1016/j.neuron.2019.05.009

Wig, G. S., Schlaggar, B. L., \& Petersen, S. E. (2011). Concepts and principles in the analysis of brain networks. Annals of the New York Academy of Sciences, 1224(1), 126-146. https://doi.org/10.1111/j.17496632.2010.05947.x

Yeo, B. T. T., Krienen, F. M., Sepulcre, J., Sabuncu, M. R., Lashkari, D., Hollinshead, M., Roffman, J. L., Smoller, J. W., Zöllei, L., Polimeni, J. R., Fischl, B., Liu, H., \& Buckner, R. L. (2011). The organization of the human cerebral cortex estimated by intrinsic functional connectivity. Journal of Neurophysiology, 106(3), 11251165. https://doi.org/10.1152/jn.00338.2011

Yu-Feng, Z., Yong, H., Chao-Zhe, Z., Qing-Jiu, C., Man-Qiu, S., Meng, L., Li-Xia, T., Tian-Zi, J., \& Yu-Feng, W. (2007). Altered baseline brain activity in children with ADHD revealed by resting-state functional MRI. Brain and Development, 29(2), 83-91. https://doi.org/10.1016/j.braindev.2006.07.002

Zalesky, A., \& Breakspear, M. (2015). Towards a statistical test for functional connectivity dynamics. Neurolmage, 114, 466-470. https://doi.org/10.1016/j.neuroimage.2015.03.047

Zalesky, A., Fornito, A., \& Bullmore, E. (2012). On the use of correlation as a measure of network connectivity. Neurolmage, 60(4), 2096-2106. https://doi.org/10.1016/j.neuroimage.2012.02.001

Zalesky, A., Fornito, A., \& Bullmore, E. T. (2010). Network-based statistic: Identifying differences in brain networks. Neurolmage, 53(4), 1197-1207. https://doi.org/10.1016/j.neuroimage.2010.06.041

Zalesky, A., Fornito, A., Cocchi, L., Gollo, L. L., \& Breakspear, M. (2014). Time-resolved resting-state brain networks. Proceedings of the National Academy of Sciences, 111(28), 10341-10346.

https://doi.org/10.1073/pnas.1400181111

Zarahn, E., Aguirre, G. K., \& D’Esposito, M. (1997). Empirical analyses of BOLD fMRI statistics. Neurolmage, 5(3), 179-197. https://doi.org/10.1006/nimg.1997.0263 